\title{
Integrated assessment of biological invasions
}

\author{
Inés Ibáñez, ${ }^{1,13}$ Jeffrey M. Diez, ${ }^{1,2}$ Luke P. Miller, ${ }^{3}$ Julian D. Olden, ${ }^{4}$ Cascade J. B. Sorte ${ }^{5}$ \\ Dana M. Blumenthal, ${ }^{6}$ Bethany A. Bradley, ${ }^{7}$ Carla M. D’Antonio, ${ }^{8}$ Jeffrey S. Dukes, ${ }^{9}$ Regan I. Early, ${ }^{10}$ \\ Edwin D. Grosholz, ${ }^{11}$ and Joshua J. Lawler ${ }^{12}$ \\ ${ }^{1}$ School of Natural Resources and the Environment, University of Michigan, Ann Arbor, Michigan 48109 USA \\ ${ }^{2}$ Institute of Integrative Biology, ETH, Zurich, Switzerland \\ ${ }^{3}$ Hopkins Marine Station, Stanford University, Pacific Grove, California 93950 USA \\ ${ }^{4}$ School of Aquatic and Fishery Sciences, University of Washington, Seattle, Washinigton 98105 USA \\ ${ }^{5}$ Department of Environmental, Earth and Ocean Sciences, University of Massachusetts, Boston, Massachusetts 02125 USA \\ ${ }^{6}$ Rangeland Resources Research Unit, USDA Agricultural Research Service, Fort Collins, Colorado 80526 USA \\ ${ }^{7}$ Department of Environmental Conservation, University of Massachusetts, Amherst, Massachusetts 01003 USA \\ ${ }^{8}$ Department of Ecology, Evolution, and Marine Biology, University of California, Santa Barbara, California 93106 USA \\ ${ }^{9}$ Department of Forestry and Natural Resources and Department of Biological Sciences, Purdue University, West Lafayette, \\ Indiana 47907 USA \\ ${ }^{10}$ Cátedra Rui Nabeiro, Universidade de Évora, Évora, Portugal \\ ${ }^{11}$ Department of Environmental Science and Policy, University of California, Davis, California 95616 USA \\ ${ }^{12}$ School of Environmental and Forest Sciences, University of Washington, Seattle, Washington 98195 USA
}

Abstract. As the main witnesses of the ecological and economic impacts of invasions on ecosystems around the world, ecologists seek to provide the relevant science that informs managers about the potential for invasion of specific organisms in their region(s) of interest. Yet, the assorted literature that could inform such forecasts is rarely integrated to do so, and further, the diverse nature of the data available complicates synthesis and quantitative prediction. Here we present a set of analytical tools for synthesizing different levels of distributional and/or demographic data to produce meaningful assessments of invasion potential that can guide management at multiple phases of ongoing invasions, from dispersal to colonization to proliferation. We illustrate the utility of data-synthesis and data-model assimilation approaches with case studies of three well-known invasive species - a vine, a marine mussel, and a freshwater crayfish-under current and projected future climatic conditions. Results from the integrated assessments reflect the complexity of the invasion process and show that the most relevant climatic variables can have contrasting effects or operate at different intensities across habitat types. As a consequence, for two of the study species climate trends will increase the likelihood of invasion in some habitats and decrease it in others. Our results identified and quantified both bottlenecks and windows of opportunity for invasion, mainly related to the role of human uses of the landscape or to disruption of the flow of resources. The approach we describe has a high potential to enhance model realism, explanatory insight, and predictive capability, generating information that can inform management decisions and optimize phase-specific prevention and control efforts for a wide range of biological invasions.

Key words: Celastrus orbiculatus; demographic framework; hierarchical Bayesian models; invasive species management; Mytilus galloprovincialis; Orconectes rusticus; risk assessment; dispersal phase; colonization phase; proliferation phase; multiple scales.

\section{INTRODUCTION}

Invasive species are considered a primary threat to biological diversity and ecosystem function (e.g., Vitousek et al. 1997, Mack et al. 2000, Sala et al. 2000); one that is expected to increase in response to greater global trade (Levine and D'Antonio 2003, Bradley et al. 2012) and projected climate change (Dukes et al. 2009, Diez et al. 2012). Mounting documentation of ecological and economic impacts of species invasions has emphasized

Manuscript received 26 April 2013; revised 10 June 2013; accepted 18 June 2013. Corresponding Editor: D. S. Schimel.

${ }^{13}$ E-mail: iibanez@umich.edu the urgent need for researchers to provide managers with meaningful recommendations for how to prevent invasions and how to prioritize management of invasive species (Papes et al. 2011). Successful curtailment of the colonization and establishment of invasive species will require early detection and rapid-response activities, whereas controlling invader spread will be most effective when focused on likely sources of propagules of new colonists (Simberloff 2009) or preventing the conditions that would allow the invasive species to dominate the native community (DeGasperis and Motzkin 2007). Thus, given an ongoing invasion the management approach should be tailored to the pertinent phase of the spread process: dispersal, colonization, or prolifer- 
ation. In general, common approaches to forecasting invasion generate an overall assessment but do not specify, even if they are included in the calculation, the likelihood of each of the phases of invasion (Olden et al. 2011, Leung et al. 2012). Hence, we are in need of an analytical approach that integrates all information available to guide management depending on the invasion phase (Lodge et al. 2006).

When sufficient demographic and distributional data are available, ecological forecasting can directly evaluate each phase of the ongoing invasion process, and help managers to make more efficient and targeted use of limited human and financial resources (Vander Zanden and Olden 2008). Unfortunately, forecasting invasions across space and time (i.e., under changing climatic conditions) is notoriously difficult because most of the available information (i.e., demographic data) is context specific; that is, unpredictable events often play an important role in the outcome of the invasion (e.g., DeGasperis and Motzkin 2007, Besaw et al. 2011). One common approach to forecasting invasions is the use of bioclimatic envelope modeling, which projects regional current and future invasion potential based on empirical relationships between species distributions and climate (Peterson and Vieglais 2001). Although bioclimatic envelope models can help us to understand abiotic constraints and to develop watch lists, most of them only consider regional suitability for invasive species establishment, as they are based on broad scale correlations between distributions and climatic factors and are often conducted at spatial scales too large for practical management applications. Furthermore, these models rarely account for important local-scale dynamics, like dispersal and community dynamics. A number of other studies have used local-scale demographic, dispersal, or disturbance models (e.g., Brook et al. 2009, Franklin 2010, Huntley et al. 2010) to assess the likelihood of species establishment and spread. However, these models are often data intensive and may not cover the full extent of management-relevant landscapes. Further, local demographic or dispersal data are rarely combined with landscape or regional analyses to create more comprehensive vulnerability assessments (but see Keith et al. 2008, Early and Sax 2011). Thus, there is a need for an analytical approach that links local demographic information with coarse-resolution models of environmental suitability.

The challenge is to operationalize an analytical framework that allows synthesis of available information and that generates a quantitative assessment, across spatial scales, of the likelihood for invasion at each phase of the invasion process. For that, demographic information about invasive species (i.e., their dispersal, survival, growth, and reproduction in different habitats and conditions) will be critical to understanding local, landscape, and regional invasion risk (Shea and Chesson 2002). Although we rarely have the data necessary to construct full demographic models (e.g., population changes over time), let alone implement them spatially, there is a wealth of information available for many species that can inform partial demographic models. For example, ecological experiments provide snapshots in time and space of complex demographic dynamics; when combined into a single assessment, these can provide a broad understanding of species performance in different environments and along the phases of the invasion process.

Here, we demonstrate a set of analytical methods that synthesize distributional and/or demographic data into a predictive assessment of species invasion (Fig. 1). In particular, we show how hierarchical models are useful for integrating disparate data sources into a single model that estimates the likelihood of the key phases of the invasion process. Our approach is conceptually akin to recent advances in data synthesis (e.g., Clark et al. 2010) and data-model integration (e.g., LaDeau et al. 2011, Luo et al. 2011) in which diverse data sets and theoretical understandings of a process are integrated into predictive models. In a hierarchical framework, empirical models can be used to define suitable habitat at regional scales, while mechanistic models can be used to assess populations or community dynamics at local scales (Pearson and Dawson 2003, Huntley et al. 2010). We can then integrate available data into spatial models to assess invasion potential into new areas or conditions (e.g., climate scenarios). We use case studies of three invasive species - the vine Celastrus orbiculatus, the mussel Mytilus galloprovincialis, and the crayfish Orconectes rusticus - to illustrate the broad utility of this approach across ecological systems and levels of information. Our main goal is to demonstrate how ecologists can combine their knowledge of the processes taking place during an ongoing invasion with available distributional and/or demographic data to provide a quantitative assessment of invasion potential at each phase (dispersal, colonization, and proliferation) that can inform management practices.

\section{Methods}

Although ongoing invasions could be best described by population dynamics models (Shea and Chesson 2002) the data required for these models are seldom available. Therefore, we focus on combining demographic and/or distribution data into quantitative estimates of invasion potential that reflect underlying demographic rates. We use hierarchical (or multilevel) models that allow us to consider multiple processes and their associated sources of uncertainty (Clark and Gelfand 2006, Clark et al. 2010). There are several key advantages of hierarchical models for this application (Gelman and Hill 2007). First, data collected at different temporal and spatial scales can be easily combined into a single demographic framework. Second, processes that were not directly observed but are important for invasion success (e.g., dispersal, recruitment, spread) may be included as latent variables. Third, these models 
Step 1:

\begin{tabular}{|c|c|c|c|c|}
\hline $\begin{array}{l}\text { Invasion } \\
\text { spread }\end{array}$ & $\begin{array}{c}\text { Demographic } \\
\text { process }\end{array}$ & $\begin{array}{c}\text { Species } \\
\text { (microsite) }\end{array}$ & $\begin{array}{c}\text { ta potentially availak } \\
\text { Habitat } \\
\text { (landscape) }\end{array}$ & $\begin{array}{l}\text { System } \\
\text { (regional) }\end{array}$ \\
\hline $\begin{array}{c}\downarrow \\
\text { Colonization } \\
\downarrow\end{array}$ & $\begin{array}{l}\text { Propagule } \\
\text { availability } \\
\downarrow \\
\downarrow \\
\text { Survival } \\
\text { Growth } \\
\downarrow\end{array}$ & $\begin{array}{l}\text { - Propagule } \\
\text { introduction } \\
\text { - Dispersal mode }{ }^{2} \\
\text { - Presencelabsence }{ }^{1,3} \\
\text { - Survival } \\
\text { - Seed/offspring size } \\
\text { - Growth rate }{ }^{2} \\
\text { - Competitive ability } \\
\\
\text { - Fecundity } \\
\text { - Percent cover }{ }^{1} \\
\end{array}$ & $\begin{array}{l}\text { - Land attributes }{ }^{1} \\
\text { Dispersal distance }{ }^{2} \\
\text { Local vector }{ }^{3} \\
\text { - Climatic suitability } \\
\text { - Habitat suitability }{ }^{1,2,3} \\
\text { - Climatic suitability } \\
\text { - Consumer pressure } \\
\text { - Resource flow }{ }^{1,2,3} \\
\text { - Resource availability } \\
\text { - Climatic suitability }\end{array}$ & $\begin{array}{l}\text { - Pathways } \\
\text { No. arrivals } \\
\text { No. individuals } \\
\text { introduced } \\
\text { - Spatiotemporal } \\
\text { patterns of arrival } \\
\text { (legacies) } \\
\text { - Global change } e^{1,2,3} \\
\\
\text { - Global change } \\
\text { - Windows of } \\
\text { opportunity } \\
\text { - Fecundity } \\
\text { - Global change } \\
\text { - Windows of } \\
\text { opportunity }{ }^{2}\end{array}$ \\
\hline
\end{tabular}

FIG. 1. Step 1. Conceptual framework for invasion assessment (left side) relating demographic rates to the ongoing invasion phases. Boxes indicate the types of data commonly available for invasive species, classified according to context (Foxcroft et al. 2011) and spatial scale. Data used in our three case studies are labeled with a superscript indicating the case study they refer to: 1 , Celastrus; 2, Mytilus; 3, Orconectes.

are flexible enough to be adapted to other systems and incorporate new data as they become available. Fourth, they help to quantify the uncertainty associated with each level in the hierarchy (individual, population, landscape, region), as well as with respect to the data sources, parameter estimates, and different model components (Clark 2005). Finally, hierarchical models can generate forecasts for different scenarios of interest (e.g., global warming, landscape change, resource availability), while concurrently containing realistic measures of uncertainty associated with the data, process, and parameters.

In our case, a hierarchical approach was also useful for organizing the available information according to the ecological scale each data set represented, for linking the data to the invasion process, and for projecting potential of an ongoing invasion at given locations for each phase of the invasive process. We focus on secondary range expansion of invasive species, that is, the processes taking place after the original introduction and establishment of the invasive species, where we identify three phases: dispersal (dispersal of propagules into new sites of the invaded range), colonization (establishment without human intervention in new sites of the invaded region forming self-sustaining populations in the wild; individuals are able to survive at a particular site or range of conditions but may not reproduce at a level that promotes further spread), and proliferation (the species grows self-sustaining populations in the wild, individuals are able to survive, reproduce and build up their populations for further spread). We describe the modeling as a three-step process and then use the three case studies, which greatly differ in the amount and type of information available, to illustrate this approach and to highlight the advantages of an integrated analysis. 
Step 1. Linking the invasion process to population demography (Fig. 1)

To relate available information - collected at several organizational levels (i.e., individuals, populations, and distributional ranges) - to ongoing invasions, we emphasize the need to link the phases in the invasion process (i.e., dispersal, colonization, and proliferation) to particular demographic parameters such as reproduction, survival, and growth (Gurevitch et al. 2011) and further to the data available on the invasion (e.g., species distribution, demographic outcomes, history of the invasion). We follow Foxcroft et al. (2011) by classifying the information available for our three study species into categories (species, habitat, and system) that define the level of biological organization and the spatial scale of the information (regional, local, and site/ microsite; Fig. 1.).

\section{Step 2. Data-model integration using hierarchical models} (Figs. 2-4)

For each species a model assessing invasive potential can be developed by combining the data available with the knowledge of the invasion process and the study system. We can then use either maximum likelihood (Cressie et al. 2009) or Bayesian (Gelman and Hill 2007) methods to estimate the parameters of the hierarchical model. For our case studies, we found the Bayesian approach to be more suitable for dealing with the large number of parameters and latent variables included in the models.

\section{Step 3. Integrated assessment of biological invasions} (Figs. 5-7)

Parameter estimates, defined by their means, variances, and covariances, can be used to predict potential for invasion at each phase of the ongoing invasion. A phasespecific index also allows for more targeted predictions of invasion potential, providing a rapid and clear identification of bottlenecks (constraining factors, e.g., lack of propagules) or windows of opportunity (favorable conditions, e.g., disturbance in the natural flow of resources) affecting the invasion phases that could then be targeted for management action.

We next briefly introduce each case study and describe the final model used to generate estimates of likelihood of invasion at each phase (Steps 1 and 2). To assess the difference between results of our integrated model and those of more traditional approaches, we also compared our results for the likelihood of colonization with those from a climate-envelope establishment model. Detailed description of the data, methods and model selection for each case study are provided in the Appendix.

\section{Case study 1: oriental bittersweet, Celastrus orbiculatus}

Celastrus orbiculatus Thunb., oriental bittersweet, is a perennial vine introduced to the United States from East Asia around 1860 (Mehrhoff et al. 2003). It was first planted as an ornamental species and soon after became naturalized. In its invasive range in the northeastern United States, it is commonly found in forest edges with high light levels, but can also grow under the forest canopy (Leicht-Young et al. 2007). Its colorful fruits persist late into the winter, constituting a reliable source of food for wildlife, which disperse the seeds locally (Greenberg et al. 2001, LaFleur et al. 2007). Its presence has been associated with landscape disturbance (Mosher et al. 2009), mainly in edge habitats where it poses a threat to native woody vegetation by girdling the trees it uses for support (Mehrhoff et al. 2003).

Step 1.-This case study, for which we have extensive distributional and demographic data illustrates how we can use most of the information available to usempirical and observational - in the development of an analytical framework that assesses potential for invasion. Specifically, we used presence/absence data and percent cover data collected in New England, northeastern United States (Mehrhoff et al. 2003), and demographic data from many empirical and observational studies (Appendix: Table A1).

Step 2 (Fig. 2).-Following the findings from previous studies (Albright et al. 2009, Ibáñez et al. $2009 b$ ), we estimated the probability of dispersal as a function of land use (i.e., the extent of urban development, which was previously shown to be a good surrogate for propagule availability once this species has been introduced into an area) and spatially explicit random effects to take into account false absences, as this species is still spreading through the region (Ibáñez et al. 2009b). Population colonization was modeled as a function of germination and establishment rates (taken from empirical studies) and the degree of site suitability based on climate. The effects of climatic variables were estimated for eight habitat types to identify differential responses to climatic variables among habitats (Ellsworth et al. 2004). We modeled species presence/absence as a function of the combined probabilities of colonization and establishment. We used the species' percentground-cover data to estimate the potential for population proliferation. Ground cover is a good measure of Celastrus' success, i.e., growth and fecundity, and we used it as an indicator of proliferation (Ibáñez et al. $2009 a, b)$. Here, percent cover was conditional on overall site suitability and also estimated as a function of the variables that have been shown to influence individual growth, i.e., the availability of resources (light and soil moisture [Leicht and Silander 2006, Ibáñez et al. 2009a], with light effects nested within each soil moisture category).

\section{Case study 2: blue mussel, Mytilus galloprovincialis}

Mytilus galloprovincialis Lamarck, the Mediterranean mussel, was first introduced outside its natural range in Europe in the mid-19th and early 20th centuries. By now, Mytilus has invaded most temperate coastlines (Branch and Stephanni 2004), including southern Africa, northeast Asia, New Zealand, and the western 


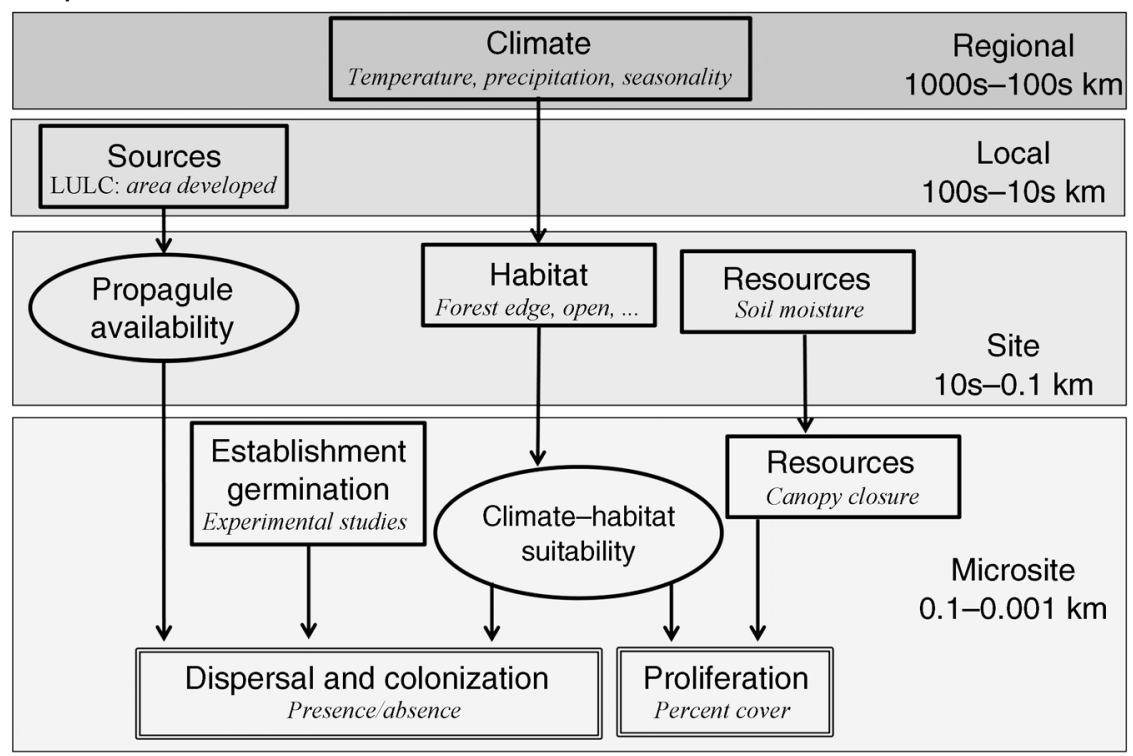

FIG. 2. Step 2. Data-model integration for the vine Celastrus orbiculatus. Boxes represent the data available (in italics; compiled in step 1) and phases of the invasive process (double outlines). Ovals represent probabilities estimated in the analysis. Arrows indicate how the different components of the model, data, processes, and output are linked across spatial scales. LULC stands for land-use-land-cover data.

coast of the United States. In its invasive range Mytilus occurs on rocky coastlines with a high rate of water flow (Carlton 1992). Given its high growth rate, large reproductive output, and relatively high thermal tolerance (Lockwood and Somero 2011, Somero 2012), this species can outcompete and replace local mussel species (van Erkom Schurink and Griffiths 1993).

Step 1.-We use this case study to illustrate how an invasion assessment can be generated solely from demographic data; there were not sufficient distributional data available for this species. Information for this species includes dispersal ranges, recruitment rates, and survival and growth rates across several geographic locations and tidal zones (i.e., height above the low tide level, Appendix: Table A4). For those studies where field data were collected $(\sim 20)$, we were able to determine the location's maximum water temperatures and chlorophyll $a$ levels (as an index of food availability; Feldman and McClain 2012). Independently from the analyses, we calculated the probability of dispersal as a function of distance to source using an exponential decay function based on observed dispersal distances (see Appendix: Table A4).

Step 2 (Fig. 3).-Colonization was modeled as a function of survival rates, which varied among tidal zones and were estimated as a function of maximum water temperature. Tidal zones represent an environmental suitability gradient based on the period of exposure to dry conditions, from most to less suitable: subtidal, low shore, mid-shore, and high shore. We used published individual growth rates as a proxy for population growth, itself our metric of proliferation. Growth rate was estimated as a function of resources (phytoplankton in the water column, using maximum chlorophyll $a$ as a proxy) and maximum water temperature, this last variable nested within tidal zone. Estimates for proliferation were then standardized to vary between 0 and 1 to represent performance with respect to the species' observed maximum growth rate.

\section{Case study 3: rusty crayfish, Orconectes rusticus}

Over the last 50 years the rusty crayfish Orconectes rusticus Girard, has spread from its historical range in the Ohio River drainage in the United States to waters throughout much of Illinois, Michigan, Wisconsin, Minnesota, and parts of 12 other states, Ontario, Canada, and the Laurentian Great Lakes (Olden et al. 2006). Once established, the highly aggressive and omnivorous feeding behavior of $O$. rusticus has altered entire lake food webs, with negative effects on benthic algae, macrophytes, aquatic invertebrates (including native crayfish) and fish (e.g., Olsen et al. 1991, Lodge et al. 1994, McCarthy et al. 2006). This crayfish reaches its physiological optimum in water temperatures between $20^{\circ}$ and $25^{\circ} \mathrm{C}$, but can tolerate temperatures between $0^{\circ}$ and $39^{\circ} \mathrm{C}$.

Step 1.- There is an extensive body of literature on Orconectes; however, for this case study we used information from the data-rich region of the state of Wisconsin (Olden et al. 2006, 2011). Detailed demographic data were lacking for this species; thus, in contrast to case study 1 above, this case study illustrates 
Spatial scales

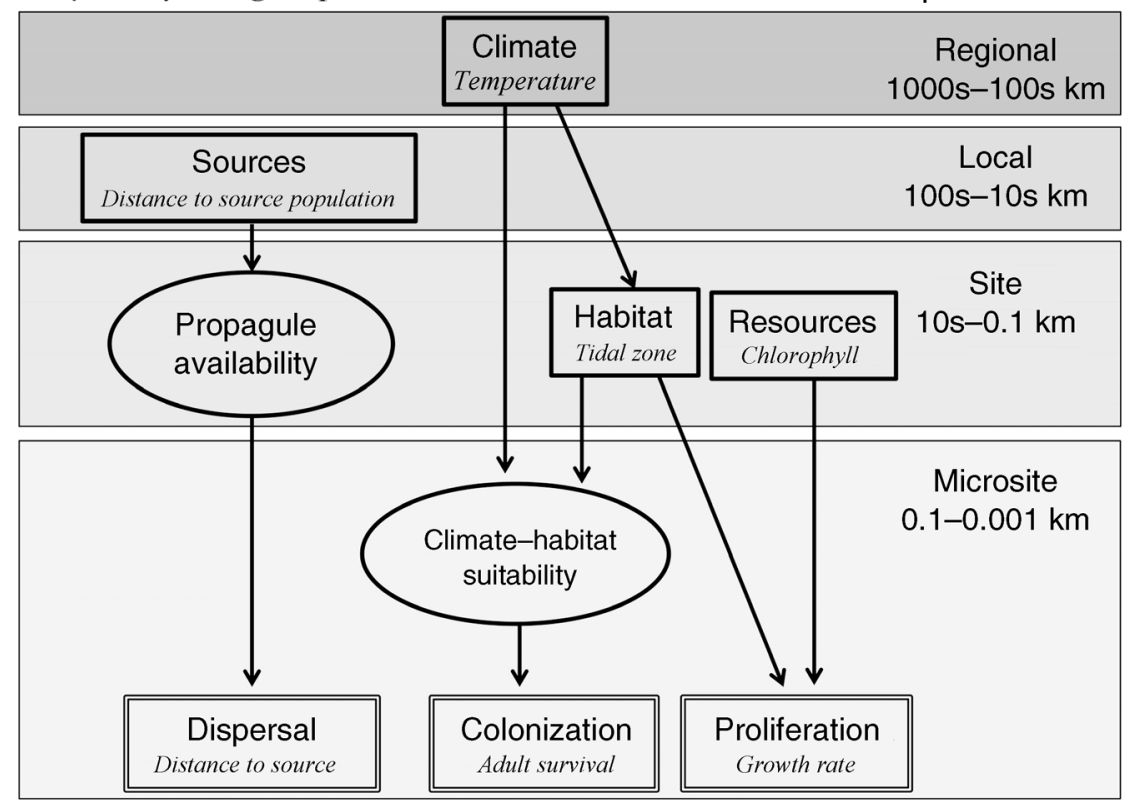

FIG. 3. Step 2. Data-model integration for the mussel Mytilus galloprovincialis. The format is as in Fig. 2. how invasion risk can be analyzed using only distributional data. We examined patterns of Orconectes presence/absence in 292 lakes. Data were also available for native crayfish species presence/absence over time (before and after the invasion of Orconectes). Olden et al. (2011) used those data to calculate an index of each lake's vulnerability to invasion: lakes that lost the native species after the invasion have a higher vulnerability index than those where the two native species still persist. We used this vulnerability index as a proxy for the invasive species' competitive ability or potential to spread once it has been introduced in a lake, with more vulnerable lakes indicating the potential for higher population growth of Orconectes.

Step 2 (Fig. 4).-We analyzed presence/absence data as the combined probability of dispersal and colonization. Following Olden et al. (2011), we estimated probability of dispersal as a function of human visitation (boat landings) where we included spatially explicit random effects. The suitability of each lake, colonization, was modeled as a function of the lake's temperature (minimum winter and maximum summer air temperatures) and of habitat type (drainage vs. seepage lake). We modeled proliferation (based on lake vulnerability) as a function of lake primary production (using Secchi disk depth as a measure of water column clarity), and conditionally based on the estimated suitability.

\section{RESULTS}

For each case study, we describe the most relevant outcomes from the analysis (Step 3; Figs. 5-7). Parameter values, additional outcomes (e.g., likelihood of invasion under different climatic scenarios), uncer- tainty around our predictions, and comparisons with the climate-envelope model projections for establishment are provided in the Appendix. Overall, and for the three case studies, an integrated analysis of potential for invasion resulted in a better fit of the data, and reduced uncertainty around those predictions, than did the climate-envelope model (based on deviance information criteria; Spiegelhalter et al. 2000). The integrated models also revealed complex interactions among the driving variables that would not have been accounted for otherwise (see particular species' results).

\section{Case study 1: oriental bittersweet, Celastrus orbiculatus}

With the parameters estimated in the model (Fig. 2), we calculated the likelihood of dispersal (as propagule availability), colonization (as climate-habitat suitability) and proliferation (as percent cover) for the entire region of New England (USA) and at a selected $10 \times 10 \mathrm{~km}$ site. We present the regional forecasts $(\sim 5 \mathrm{~km}$ grid $)$ under current climate and landscape configuration and the most suitable conditions for this species (edge habitat, dry soils, and open canopies) (Fig. 5 right panel). The local forecast incorporates the actual habitats, soils, canopies, landscape configurations, and climate at that site (Fig. 5 left panels). These local forecasts also show the interactions among driving variables, and how they affect each phase differently (relatively high suitability for colonization based only on climate and habitat, but low potential for proliferation when the actual resources are also accounted for). By tracking the different sources of uncertainty in the data, processes and parameters, we are also able to report the uncertainty associated with our predictions (represented 


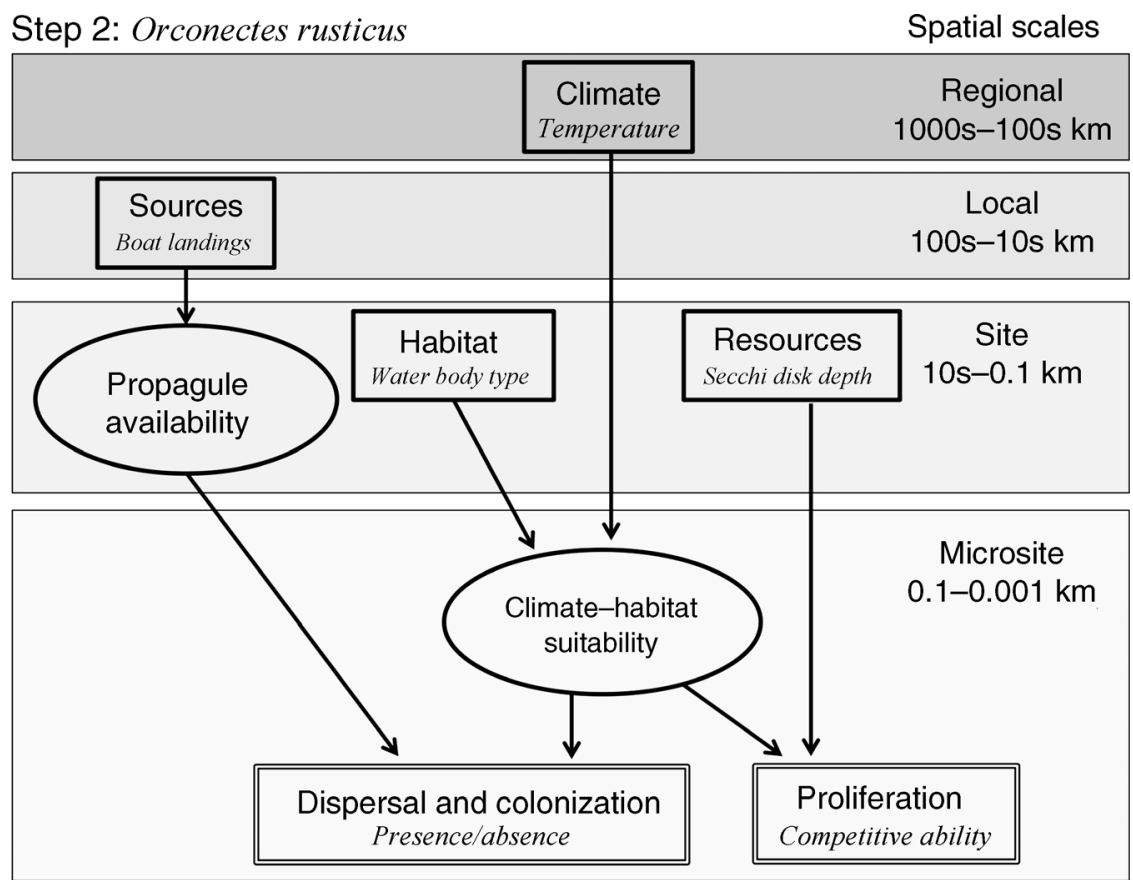

FIg. 4. Step 2. Data-model integration for the crayfish Orconectes rustiscus. The format is as in Fig. 2.

as standard deviations of the mean predictions; Fig. 5, see discussion below).

Step 3.- The probability of dispersal by Celastrus (Fig. 5 top row of maps), based on developed land, is fairly high across the region as well as in the highlighted $10 \times 10 \mathrm{~km}$ site, although it substantially drops from $0.8-1$ to $0.4-0.5$ in the most isolated areas. Regional predictions of colonization, expressed as climate and habitat suitability strongly reflect climatic isoclines (Fig. 5 middle row, large regional map), whereas local predictions reflect the effect of varying habitat (Fig. 5 middle row, insets). Predictions of percent cover, our proxy for proliferation, also varied across climatic isoclines at the regional scale, but reflected patterns of resource availability, i.e., light, at the local scale (Fig. 5 bottom row). Uncertainty in our regional predictions (Fig. 5, small regional maps) is higher in the north for colonization and spread, likely reflecting the lower density of data points in those areas (and climates, data not shown), while the low uncertainty associated with the likelihood of establishment in the north is probably due to the low climatic suitability of this area. The uncertainty associated with the local predictions (Fig. 5 left-most column of insets) is generally lower than that for the regional estimates because more site information is included in local predictions.

\section{Case study 2: blue mussel, Mytilus galloprovincialis}

For the blue mussel we estimated colonization as the species' survival based on climate and habitat suitability, and potential for proliferation as the species' relative growth performance based on resources and on climate and habitat suitability (Fig. 3). We then multiplied these estimates by the probability of dispersal (calculated as a function of distance to larval source), to estimate relative invasion potential with respect to distance to source given a gradient of temperatures, chlorophyll $a$ levels, and habitat types (Fig. 6).

Step 3.-Colonization, based on predicted survival reflecting climate-habitat suitability of Mytilus did not follow the expected suitability gradient, from sub-tidal to high shore. Suitability decreases from the sub-tidal to the mid-shore zone, but increases in the high-shore habitat (Fig. 6, top row). Changes in maximum water temperature are important in determining establishment in the low and mid-shores, as this species is favored over its competitors at high temperature. Growth performances, our measurement of potential to proliferate, responded positively to both chlorophyll $a$ levels and maximum water temperature (Fig. 6, middle and bottom rows). These effects also varied with tidal zone; there is a gradual decline in the estimate for spread, from the subtidal habitat to the high shore and from high to low temperatures. Uncertainty estimates associated with the predictions are included in the Appendix.

\section{Case study 3: rusty crayfish, Orconectes rusticus}

For the rusty crayfish we generated invasion assessment values for dispersal, colonization and proliferation, under current and varying conditions: warmer climate $\left(+3^{\circ} \mathrm{C}\right.$ in winter minimum and summer maximum temperatures), increased lake visitation (20\% increase in 
Step 3

Local predictions

\section{Regional predictions}
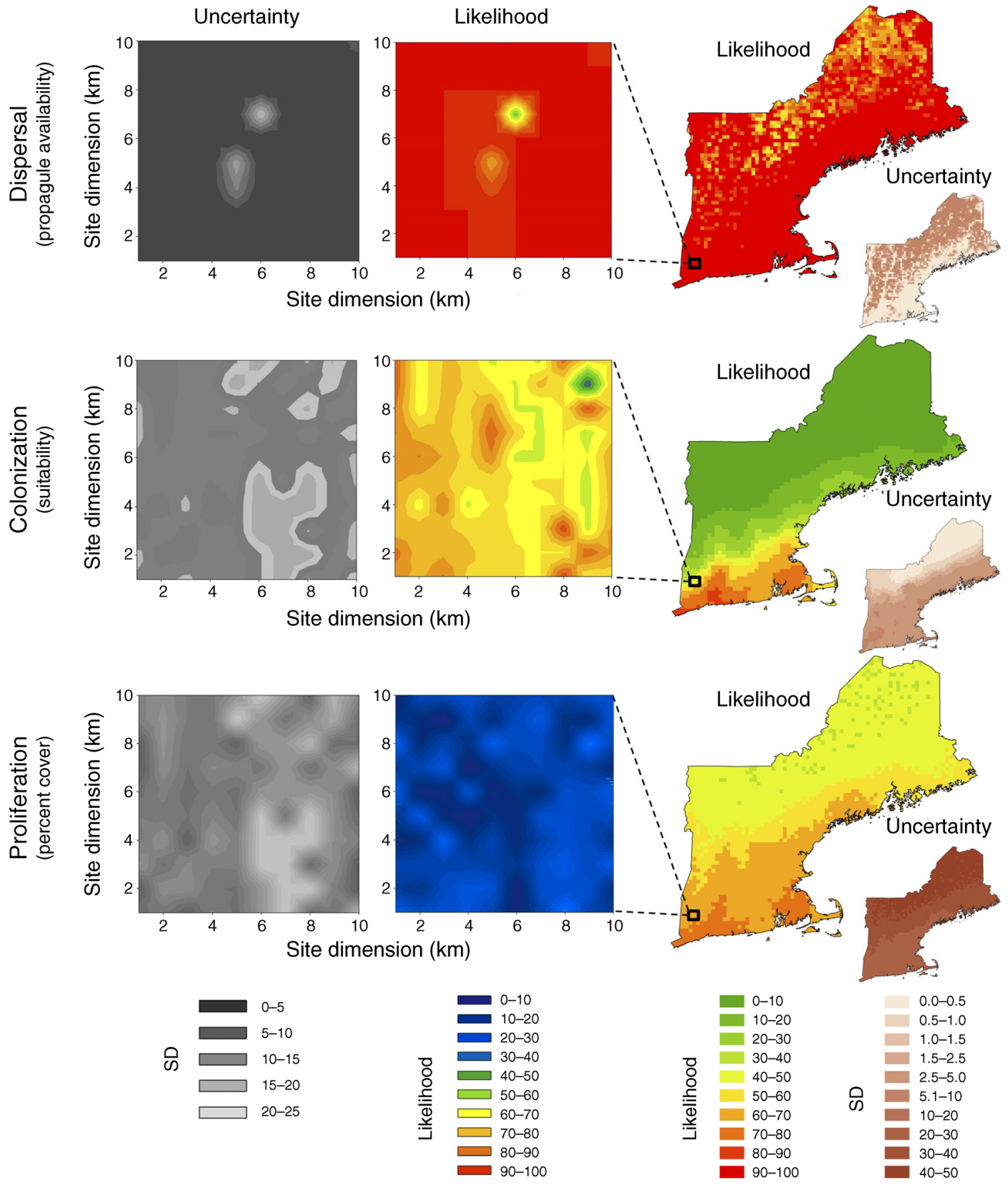

FIG. 5. Step 3. Invasion assessment of Celastrus in the region of New England (USA) and for a $10 \times 10 \mathrm{~km}$ local site within the region. Posterior mean estimates and standard deviations (uncertainty) are provided for the likelihood of (top panels) dispersal (determined by propagule availability), of (middle panels) colonization (estimated as climate-habitat suitability), and of (bottom panels) proliferation (modeled as percent cover).

boat landings), and increased resources (20\% decrease in Secchi disk depth, implying greater water column primary productivity represented by lower water clarity).

Step 3.- Model results underline the high likelihood of colonization, based on climate and habitat suitability, for rusty crayfish in Wisconsin lakes (Fig. 7). Results also highlight potential bottlenecks and windows of opportunity in the invasion process of this species. Dispersal and proliferation potentials are relatively low, indicating that management efforts should focus mainly 


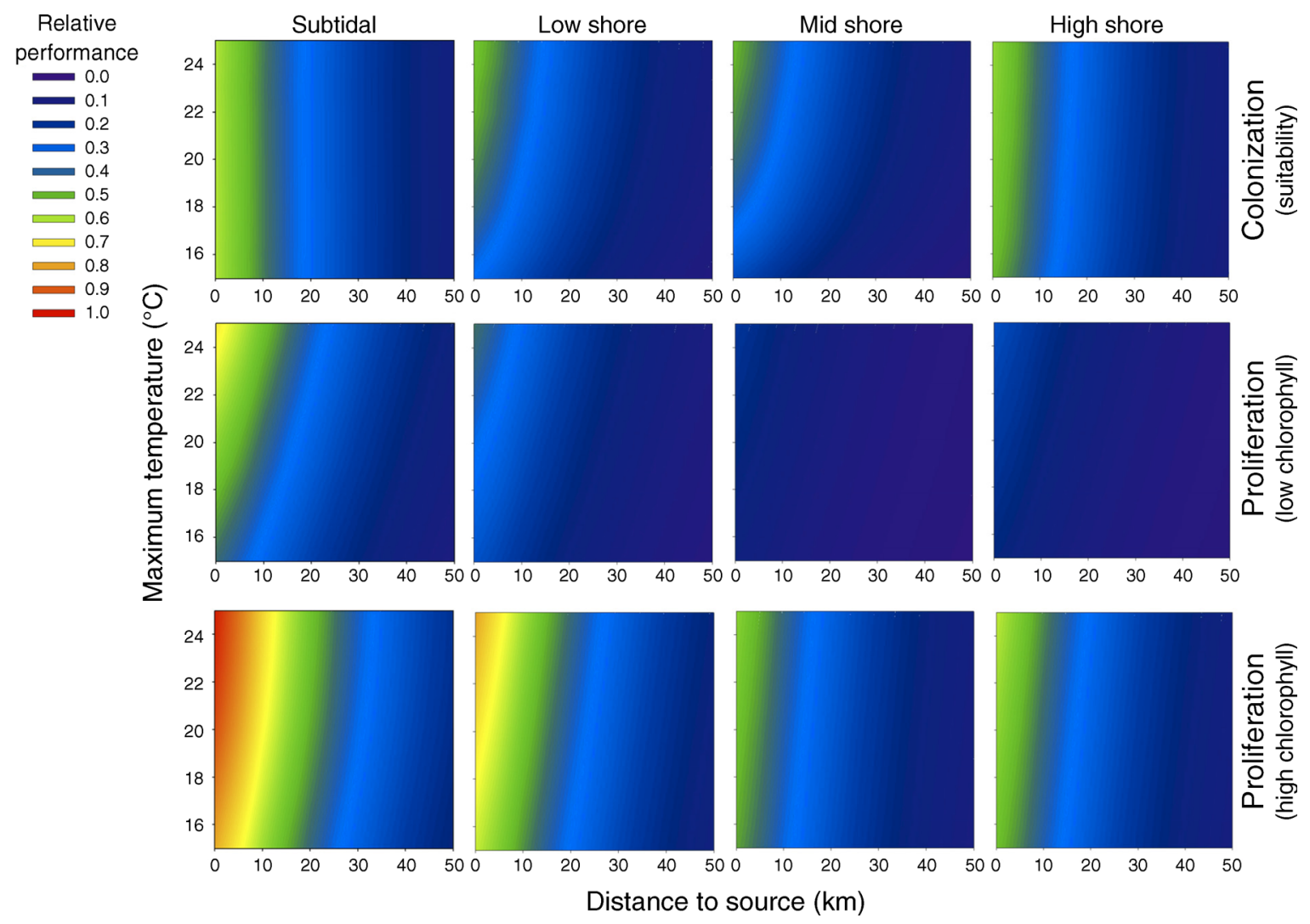

FIG. 6. Step 3. Relative performance for Mytilus invasion as a function of distance to larval sources and maximum sea-surface temperature, for each tidal zone and varying maximum chlorophyll levels, shown as (top panel) predicted mean likelihood of colonization (estimated as climate-habitat suitability) and (middle and bottom panels) proliferation (modeled as relative growth performance). See Appendix for uncertainty estimates.

on preventing the introduction of the species and/or the eutrophication of the lakes. In the future scenarios, colonization and spread potentials increase in response to more boat landings and resources, respectively (Fig. 7 bottom panels). However, climate habitat suitability affecting colonization would decrease as temperatures rise, as increased summer maximum temperatures reduced the lake's likelihood of invasion. Increase in winter minimum temperatures had a positive, but not significant, effect on invasion risk, and was less important than summer maximum temperature (see Appendix for parameter estimates).

\section{Discussion}

Our study introduces and demonstrates an analytical approach that facilitates the integration of available data with model structures describing the invasion process. In particular, our approach has a high potential to enhance model realism, explanatory insight, and predictive capability together with an explicit evaluation of uncertainty associated with different predictor variables. Using available distributional data and/or experimental and observational demographic studies, we were able to quantitatively evaluate each phase of the invasion process in conjunction with the others. By accounting for the three phases of the ongoing invasion simultaneously, and by including multiple data sources, our approach indirectly considers feedbacks and interactions between the phases and demographic stages. As a result, model predictions fit the data better than those of a climate-envelope model of colonization, and also generated emergent predictions that would not be gleaned from the simpler model alone. For example, while we found that edge habitats were optimal for the vine Celastrus orbicularis in the south (as expected from previous work; Leicht-Young et al. 2007) the most suitable habitat in the north switched towards forest habitats due to their interaction with climate (see Appendix: Fig. A2). Furthermore, as all phases of invasion were modeled as statistical probabilities, the final outcomes provided an integrated measure and associated uncertainties of success at each phase of invasion. The resulting phase-specific estimates for each species can now inform invasive-species management strategies, for example by targeting edge habitats in the southern portion of Celastrus' invaded range, but forest habitats further north. 


\section{Enhanced model realism}

In the past we have made use of indirect relationships (e.g., distribution and climate) to predict invasion as a function of environmental conditions. However, these relationships may vary across the distributional range of a species and along local landscapes or habitats. Thus, estimating the effects of broad-scale variables like climate in the context of site-specific factors, e.g., habitat, tidal zone, can help us to better forecast the invasion process. In our case studies we made use of hierarchical models and available demographic and/or distributional data to take into account these relationships across scales and better represent the effects of climate on the invasion process.

Our integrated assessment also incorporated knowledge about the effects of resource availability on the proliferation of the invasive species. The availability of resources is vital to successful invasions (Shea and Chesson 2002), particularly high resource availability (Hobbs and Huenneke 1992, Davis et al. 2000, Daehler 2003, Blumenthal et al. 2009), and invasion success is also frequently linked to a disruption of the regular pattern of resource supply (Sher and Hyatt 1999). Our results reflected the importance of resource availability for all three species, each of which showed positive responses to increasing resources. And, for two of the species, Celastrus and Orconectes, the flow of resources was related to human disturbance.

\section{Enhanced explanatory insight}

For two of the studied species, the vine and the mussel, we estimated the effects of regional environmental variables for each of the site-specific habitats represented in the data. Climatic variables affected the performance of both species' differently across habitats. For example, for Celastrus, the vine (Appendix: Table A3), higher annual precipitation had a positive effect in some habitats (e.g., forest edges and abandoned sites, probably because these habitats have higher evapotranspiration rates and desiccation may be a factor affecting establishment and growth), while reducing performance in others (open wetlands, where excess water could be detrimental). In the case of the mussel species Mytilus galloprovincialis, we observed a nonlinear response to the environmental temperature gradient along the habitat types considered. Such a pattern is likely the result of interactions among influences other than just environmental suitability, and probably reflects the combined effect of the environmental conditions and species interactions (i.e., competition and predation) associated with each tidal zone.

The crayfish Orconecte rusticus showed a contrasting seasonal response to climatic variables related to temperature. Warmer winter temperature favored this species, but warmer summer temperatures seemed to have a detrimental effect, and the magnitude of this effect was higher than that of warmer winter conditions. These results agree with the distributional pattern observed in the data, where most of the recent invasions took place in northern, i.e., colder, lakes (data not shown; Olden et al. 2011). Thus, as it is the combined, and opposite, effect of winter and summer temperatures that will affect this species, it is critical that we quantify interactive seasonal effects on the invasion.

The particular species' response to changes in its environment also allowed us to gain more insight into the invasion process. Landscape fragmentation brought an increase in forest edge habitat - an environment in which Celastrus thrives mainly due to higher light availability. Competitive ability of Orconectes was positively associated with an indirect measure of primary productivity of the water bodies (water clarity), to which major disruptions are mostly caused by input from human activities (e.g., residential and agricultural runoff). Mytilus also responded to higher levels of resources, in this case driven by natural upwelling processes along coasts.

\section{Enhanced predictive capability}

Changes in climate will likely affect invasive species' overall performance, especially if such changes alter the availability of resources (Sorte et al. 2013). Results from this integrated assessment allowed us to consider and quantify the potential for invasion under different climate and resource scenarios, and thus inform management about future, as well as current, invasion potential. For example, in New England colonization by Celastrus could increase significantly under warmer and drier conditions, but it is not likely to benefit if conditions become only slightly warmer (see Appendix for predictive outputs). Mytilus thrived at the high end of temperatures included in our data, meaning that global warming may increase colonization at its current range and open new grounds for invasion at higher latitudes. With respect to Orconectes, predictions will be more complex: a year-round increase in temperature might have a slightly negative effect on this species, but the ultimate outcome will depend on the net effects of beneficial winter warming and detrimental summer warming.

\section{Management implications of the integrated assessment}

Integrated assessments such as those presented here can inform management practices at multiple spatial scales by identifying vulnerable locations at the local scales and assessing risk of invasion at local to regional scales (Lodge et al. 2006, Leung et al. 2012). Anticipatory forecasts allow targeted surveys for early detection, and consequently rapid responses, which are the most effective form of invasive management (Simberloff 2009). If the different phases of the ongoing invasion are considered, management plans can be designed to target bottlenecks or windows of opportunity. For example, dispersal events limit the invasion of Wisconsin lakes by Orconectes, so management efforts could promote a boat-inspection program at boat landings 

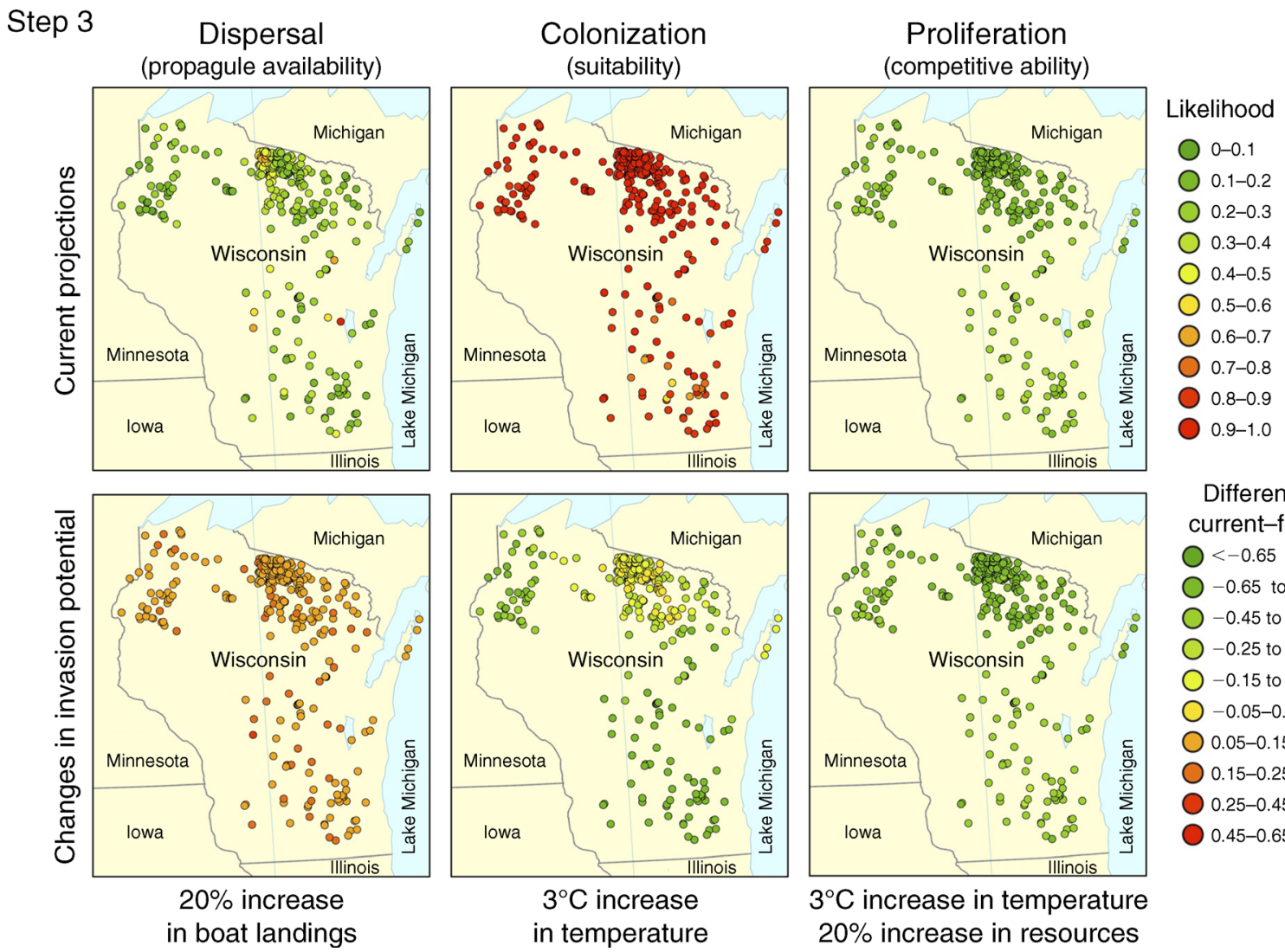

Differences current-future $0<-0.65$ O -0.65 to -0.45 O -0.45 to -0.25 O -0.25 to -0.15 -0.15 to -0.05 O $-0.05-0.05$ O $0.05-0.15$ O $0.15-0.25$ $0.25-0.45$ $0.45-0.65$

FIG. 7. Step 3. (Top panels) Estimated likelihood of each individual invasion phase, dispersal (determined by boat landings), colonization (estimated as climate and habitat suitability) and proliferation (modeled as competitive ability), for Orconectes in 292 Wisconsin (USA) lakes. (Bottom panels) Predicted changes in invasion potential (current-future) at each phase given future scenarios of increased boat landings, temperatures, and resources. See Appendix for uncertainty estimates.

(Rothlisberger et al. 2010). By including changes in resource availability in our models, we also quantitatively estimated the effect of human disturbance on the actual invasion. These estimates could facilitate management decisions, e.g., to prevent or reduce humancaused disturbances that increase resources (discharge to lakes in the case of the crayfish), to monitor areas of high disturbance (forest edges as habitats for the plant species), or to monitor sites more intensively when resources naturally increase (algal blooms in the case of the mussel).

Specifically, our results identified combinations of habitat and environmental conditions most susceptible to invasion, including areas that could be targeted for monitoring and early eradication efforts at particular times. For example, edge habitats in wet years or open wetlands in dry years would be prime sites for Celastrus invasion, or edge habitats in the south and forested habitats in the north. Warmer water temperatures will likely favor the colonization and proliferation of Mytilus, thus managers in areas with small populations of this species should be aware of potential for population growth if temperatures rise. And, in the case of Orconectes, unusually warm winters would be of concern but only if summer temperatures remain low.

In addition to highlighting the most sensitive phases and transitions in the invasion process, hierarchical models can be tailored to particular management situations, and the effects of a specific management practice that would affect any of the demographic stages considered could be easily incorporated into the modeling framework. Parameter estimates from the case studies described here, for example, could be used to generate more targeted predictions of invasion potential in specific areas, e.g., a natural park managed by local authorities, or conditions, e.g., after an unexpected disturbance event that creates a pulse of resources.

\section{Conclusions}

Although data limitations are a common problem in invasion biology, even small quantities of information, placed within a demographic framework, can facilitate invasion assessment by taking into account the basic ecological principles driving the dispersal, colonization, and proliferation phases of a particular ongoing invasion. Our technique integrates demographic and or 
distributional data with knowledge about ecosystems or processes, providing estimates of invasion potential that can be used in management. Assessments can also highlight areas where more information is needed (e.g., Celastrus performance in the northern part of the invasive range; rates of predation on Mytilus along tidal zones; effects of extreme temperature events on Orconectes). Our demographic approach employs data synthesis and data-model assimilation to make use of existing information, providing a general framework for generating integrated assessments of the likelihood of biological invasions.

\section{ACKNOWLEDGMENTS}

We thank N. Molinari and S. Jones for their feedback during the early discussions of this project, the Climate and Invasions Working Group-National Center for Ecological Analysis and Synthesis, NSF (Grant \#EF-0553768), and the University of California-Santa Barbara.

\section{Literature Cited}

Albright, T. P., D. P. Anderson, N. S. Keuler, S. M. Pearson, and M. G. Turner. 2009. The spatial legacy of introduction: Celastrus orbiculatus in the southern Appalachians, USA. Journal of Applied Ecology 46:1229-1238.

Besaw, L. M., G. C. Thelen, S. Sutherland, K. Metlen, and R. M. Callaway. 2011. Disturbance, resource pulses and invasion: short-term shifts in competitive effects, not growth responses, favour exotic annuals. Journal of Applied Ecology 48:998-1006.

Blumenthal, D., C. E. Mitchell, P. Pysek, and V. Jarosik. 2009. Synergy between pathogen release and resource availability in plant invasion. Proceedings of the National Academy of Sciences USA 106:7899-7904.

Bradley, B. A., et al. 2012. Global change, global trade, and the next wave of plant invasions. Frontiers in Ecology and the Environment 10:20-28.

Branch, G. M., and C. N. Steffani. 2004. Can we predict the effects of alien species? A case-history of the invasion of South Africa by Mytilus galloprovincialis (Lamarck). Journal of Experimental Marine Biology and Ecology 300:189-215.

Brook, B. W., H. R. Akcakaya, D. A. Keith, G. M. Mace, R. G. Pearson, and M. B. Araujo. 2009. Integrating bioclimate with population models to improve forecasts of species extinctions under climate change. Biology Letters 23:723-725.

Carlton, J. T. 1992. Introduced marine and estuarine mollusks of North America: an end-of-the-20th-century perspective. Journal of Shellfish Research 11:489-505.

Clark, J. S. 2005. Why environmental scientists are becoming Bayesians. Ecology Letters 8:2-14.

Clark, J. S., et al. 2010. High-dimensional coexistence based on individual variation: a synthesis of evidence. Ecological Monographs 80:569-608.

Clark, J. S., and A. E. E. Gelfand. 2006. Hierarchical Modelling for the Environmental Sciences Statistical methods and applications. Oxford University Press, Oxford, UK.

Cressie, N., C. A. Calder, J. S. Clark, J. M. V. Hoef, and C. K. Wikle. 2009. Accounting for uncertainty in ecological analysis: the strengths and limitations of hierarchical statistical modeling. Ecological Applications 19:553-570.

Daehler, C. C. 2003. Performance comparisons of co-occurring native and alien plants: Implications for conservation and restoration. Annual Review of Ecology, Evolution, and Systematics 34:183-211.

Davis, M. A., J. P. Grime, and K. Thompson. 2000. Fluctuating resources in plant communities: a general theory of invasibility. Journal of Ecology 88:528-536.
DeGasperis, B. G., and G. Motzkin. 2007. Windows of opportunity: historical and ecological controls on Berberis thunbergii invasions. Ecology 88:3115-3125.

Diez, J. M., et al. 2012. Will extreme climatic events facilitate biological invasions? Frontiers in Ecology and the Environment 10:249-257.

Dukes, J. S., et al. 2009. Responses of insect pests, pathogens, and invasive plant species to climate change in the forests of northeastern North America: What can we predict? Canadian Journal of Forest Research 39:231-248.

Early, R., and D. F. Sax. 2011. Analysis of climate paths reveals potential limitations on species range shifts. Ecology Letters 14:1125-1133.

Ellsworth, J. W., R. A. Harrington, and J. H. Fownes. 2004. Survival, growth and gas exchange of Celastrus orbiculatus seedlings in sun and shade. American Midland Naturalist 151:233-240.

Feldman, G., and C. McClain. 2012. Ocean Color Web, MODISAqua Reprocessing R2010.0. N. Kuring and S. W. Bailey, editors. http://gcmd.gsfc.nasa.gov/KeywordSearch/Keywords. do?Portal=GCMD\&KeywordPath=Parameters $\mid$ OCEANS $\mid$ OCEAN+CHEMISTRY $\mid$ CHLOROPHYLL\&MetadataType= $0 \&$ Columns $=0 \&$ lbnode $=$ mdlb6\#maincontent

Foxcroft, L. C., S. T. A. Pickett, and M. L. Cadenasso. 2011. Expanding the conceptual frameworks of plant invasion ecology. Perspectives in Plant Ecology, Evolution and Systematics 13:89-100.

Franklin, J. 2010. Moving beyond static species distribution models in support of conservation biogeography. Diversity and Distributions 16:321-330.

Gelman, A., and J. Hill. 2007. Data analysis using regression and multilevel/hierarchical models. Cambridge University Press, New York, New York, USA.

Greenberg, C. H., L. M. Smith, and D. J. Levey. 2001. Fruit fate, seed germination and growth of an invasive vine - an experimental test of "sit and wait" strategy. Biological Invasions 3:363-372.

Gurevitch, J., G. A. Fox, G. M. Wardle, and T. D. Inderjit. 2011. Emergent insights from the synthesis of conceptual frameworks for biological invasions. Ecology Letters 14:407418.

Hobbs, R. J., and L. F. Huenneke. 1992. Disturbance, diversity, and invasion: implications for conservation. Conservation Biology 6:324-337.

Huntley, B., et al. 2010. Beyond bioclimatic envelopes: dynamic species' range and abundance modelling in the context of climatic change. Ecography 33:621-626.

Ibáñez, I., J. A. Silander, J. M. Allen, S. A. Treanor, and A. Wilson. 2009b. Identifying hotspots for plant invasions and forecasting focal points of further spread. Journal of Applied Ecology 46:1219-1228.

Ibáñez, I., J. A. Silander, A. M. Wilson, N. LaFleur, N. Tanaka, and I. Tsuyama. 2009a. Multivariate forecasts of potential distributions of invasive plant species. Ecological Applications 19:359-375.

Keith, D. A., H. R. Akçakaya, W. Thuiller, G. F. Midgley, R. G. Pearson, S. J. Phillips, H. M. Regan, M. B. Araújo, and T. G. Rebelo. 2008. Predicting extinction risks under climate change: coupling stochastic population models with dynamic bioclimatic habitat models. Biology Letters 4:560563.

LaDeau, S. L., G. E. Glass, N. T. Hobbs, A. Latimer, and R. S. Ostfeld. 2011. Data-model fusion to better understand emerging pathogens and improve infectious disease forecasting. Ecological Applications 21:1443-1460.

Lafleur, N. E., M. A. Rubega, and C. S. Elphick. 2007. Invasive fruits, novel foods, and choice: an investigation of European starling and American Robin frugivory. Wilson Journal of Ornithology 119:429-438.

Leicht, S. A., and J. A. Silander. 2006. Differential responses of invasive Celastrus orbiculatus (Celastraceae) and native $C$. 
scandens to changes in light quality. American Journal of Botany 93:972-977.

Leicht-Young, S. A., J. A. Silander, and A. M. Latimer. 2007. Comparative performance of invasive and native Celastrus species across environmental gradients. Oecologia 154:273282.

Leung, B., et al. 2012. TEASIng apart alien species risk assessments: a framework for best practices. Ecology Letters 15:1475-1493.

Levine, J. M., and C. M. D'Antonio. 2003. Forecasting biological invasions with increasing international trade. Conservation Biology 17:322-326.

Lockwood, B. L., and G. N. Somero. 2011. Invasive and native blue mussels (genus Mytilus) on the California coast: the role of physiology in a biological invasion. Journal of Experimental Marine Biology and Ecology 400:167-174.

Lodge, D. M., J. W. Kershner, J. E. Aloi, and A. P. Covich. 1994. Effects of an omnivorous crayfish (Orconectes rusticus) on a freshwater littoral food web. Ecology 75:1265-1281.

Lodge, D. M., et al. 2006. Biological invasions: Recommendations for U.S. policy and management. Ecological Applications 16:2035-2054.

Luo, Y., K. Ogle, C. Tucker, S. Fei, C. Gao, S. LaDeau, J. S. Clark, and D. S. Schimel. 2011. Ecological forecasting and data assimilation in a data-rich era. Ecological Applications 21:1429-1442.

Mack, R. N., D. Simberloff, W. M. Lonsdale, H. Evans, M. Clout, and F. A. Bazzaz. 2000. Biotic invasions: causes, epidemiology, global consequences, and control. Ecological Applications 10:689-710.

McCarthy, J. M., C. L. Hein, J. D. Olden, and M. J. Vander Zanden. 2006. Coupling long-term studies with meta-analysis to investigate impacts of non-native crayfish on zoobenthic communities. Freshwater Biology 51:224-235.

Mehrhoff, L. J., J. A. Silander, Jr., S. A. Leicht-Young, E. S. Mosher, and N. M. Tabak. 2003. IPANE: invasive plant atlas of New England. Department of Ecology and Evolutionary Biology, University of Connecticut, Storrs, Connecticut, USA. http://www.ipane.org

Mosher, E. S., J. A. Silander, Jr., and A. Latimer. 2009. The role of land-use history in major invasions by woody plant species in the northeastern North American Landscape. Biological Invasions 11:2317-2328.

Olden, J. D., J. M. McCarthy, J. T. Maxted, W. W. Fetzer, and M. J. Vander Zanden. 2006. The rapid spread of rusty crayfish (Orconectes rusticus) with observations on native crayfish declines in Wisconsin (USA) over the past 130 years. Biological Invasions 8:1621-1628.

Olden, J. D., M. J. Vander Zanden, and P. T. J. Johnson. 2011. Assessing ecosystem vulnerability to invasive rusty crayfish (Orconectes rusticus). Ecological Applications 21:2587-2599.
Olsen, T. M., D. M. Lodge, G. M. Capelli, and R. J. Houlihan. 1991. Mechanisms of impact of an introduced crayfish (Orconectes rusticus) on littoral congeners, snails, and macrophytes. Canadian Journal of Fisheries and Aquatic Sciences 48:1853-1861.

Papeş, M., M. Sallstrom, T. R. Asplund, and M. J. Vander Zanden. 2011. Invasive species research to meet the needs of resource management and planning. Conservation Biology 25:867-872.

Pearson, R. G., and T. P. Dawson. 2003. Predicting the impacts of climate change on the distribution of species: Are bioclimate envelope models useful? Global Ecology and Biogeography 12:361-371.

Peterson, A. T., and D. A. Vieglais. 2001. Predicting species invasions using ecological niche modeling: new approaches from bioinformatics attack a pressing problem. BioScience 51:363-371.

Rothlisberger, J. D., W. L. Chadderton, J. McNulty, and D. M. Lodge. 2010. Aquatic invasive species transport via trailered boats: what is being moved, who is moving it, and what can be done. Fisheries 35:121-132.

Sala, O., et al. 2000. Global biodiversity scenarios of the year 2100. Science 287:1770-1774.

Shea, K., and P. Chesson. 2002. Community ecology theory as a framework for biological invasions. Trends in Ecology and Evolution 17:170-176.

Sher, A. A., and L. A. Hyatt. 1999. The disturbed resource-flux invasion matrix: a new framework for patterns of plant invasion. Biological Invasions 1:107-114.

Simberloff, D. 2009. The role of propagule pressure in biological invasions. Annual Review of Ecology, Evolution, and Systematics 40:81-102.

Somero, G. N. 2012. The physiology of global change: linking patterns to mechanisms. Annual Review of Marine Science $4: 39-61$.

Sorte, C. J. B., et al. 2013. Poised to prosper? A cross-system comparison of climate change effects on native and nonnative species performance. Ecology Letters 16:260-271.

Spiegelhalter, D. J., N. Best, B. P. Carlin, and A. V. D. Linde. 2000. Bayesian measures of model complexity and fit. Journal of the Royal Statistical Society: Series B 64:583-639.

Vander Zanden, M. J., and J. D. Olden. 2008. A management framework for preventing the secondary spread of aquatic invasive species. Canadian Journal of Fisheries and Aquatic Sciences 65:1512-1522.

van Erkom Schurink, C., and C. L. Griffiths. Factors affecting relative rates of growth in four South African mussel species. Aquaculture International 109:257-273.

Vitousek, P. M., H. A. Mooney, J. Lubchenco, and J. M. Melillo. 1997. Human domination of Earth's ecosystems. Science 277:494-499.

\section{Supplemental Material}

\section{Appendix}

Detailed description of the three case studies, data, models, and additional results (Ecological Archives A024-001-A1). 